\title{
Operation technological process research in the cleaning system of the grain combine
}

\author{
Ildar Badretdinov, ${ }^{1}$ Salavat Mudarisov, ${ }^{2}$ Eduard Khasanov, ${ }^{2}$ Ruslan Nasyrov, ${ }^{2}$ Marat Tuktarov ${ }^{3}$ \\ ${ }^{1}$ Department of Mathematics; ${ }^{2}$ Department of Road Construction; ${ }^{3}$ Department of Electric Machines and Equipment, \\ Federal State Budgetary Educational Establishment of Higher Education 'Bashkir State Agrarian University', Ufa, \\ Russia
}

\begin{abstract}
The purpose of this study is to increase the efficiency of the technological process of a combine harvester cleaning system. It involved the simulation of the actual work process, the identification of problem areas and the uniform airflow distribution across the width of the sieve mill. The method for determining the class of 'air-grain heap' flow in the combine harvester cleaning system is presented in order to provide the mathematical description of its technical work process. As a result, the volumetric $\left(\mathrm{Q}=8 \cdot 10^{-6} \div\right.$ $\left.2.5 \cdot 10^{-4}\right)$ and mass $(\mathrm{W}=0.01 \div 0.3)$ concentration of a grain heap in different sections of the sieve mill of the combine harvester cleaning system. The experimental measurements of the airflow speed on the sieve mill's surface for the existing structures of the cleaning system in modern grain harvesters were $3.75 \div 10.2 \mathrm{~m} / \mathrm{s}$. The data obtained will be used in the future to implement a mathematical model for a complete description of the technological process of a combine harvester cleaning system using methods based on two-phase flow mechanics.
\end{abstract}

Correspondence: Ildar Badretdinov, Department of Mathematics, Federal State Budgetary Educational Establishment of Higher Education 'Bashkir State Agrarian University', 50-letia Octyabrya Str., 34, Ufa 450001, Russia. E-mail: badretdinovild876@rambler.ru

Key words: Airflow; centrifugal fan; cleaning system; combine harvester; mathematical model; modeling of the technological process.

Funding: this research did not receive any specific grant from funding agencies in the public, commercial, or not-for-profit sectors.

Conflict of interests: the authors declare no potential conflict of interests.

Received for publication: 13 October 2020.

Accepted for publication: 10 March 2021.

(C) Copyright: the Author(s), 2021

Licensee PAGEPress, Italy

Journal of Agricultural Engineering 2021; LII:1129

doi:10.4081/jae.2021.1129

This article is distributed under the terms of the Creative Commons Attribution Noncommercial License (by-nc 4.0) which permits any noncommercial use, distribution, and reproduction in any medium, provided the original author(s) and source are credited.

\section{Introduction}

In the grain harvesters $(\mathrm{GH})$, the separation of the grain heap from coarse impurities (spikelets, straw residues, etc.) and light impurities (husks, small weed seeds, etc.) takes place in the cleaning system by means of an air sieve. The existing designs of airsieve cleaning systems have several significant disadvantages in relation to the quality of the technological process for separating the grain heap from impurities. Many variables can be present, such as increased throughput, improper adjustments, uneven crop ripening, uneven grain heaps to be cleaned, different concentration of particles (grain and impurities). We can also add moisture and clogging of the grain heap, uneven distribution of the grain heap along the sieve mill's width, when harvesting on slopes. All these issues are due to the uneven distribution of the airflow and the width of the sieves due to the imperfection of existing designs of the cleaning system and the lack of a complete theoretical description and methods for substantiating design and technological parameters (Alferov, 1987; Kutzbach and Quick, 1999; Kutzbach, 2001; Rademacher, 2003; Feiffer et al., 2005; Kelemen et al., 2005; Miu and Kutzbach, 2008; Steponavičius et al., 2008; Voicu et al., 2008; Kotov and Chaus, 2010; Mudarisov and Badretdinov, 2013; Vasilevskij et al., 2013; FAO Report, 2014; Mirzazadeh et al., 2015; Baran et al., 2016; Špokas et al., 2016; Korn and Herlitzius, 2017; Sorochenko, 2017; Aldoshin and Lylin, 2018; Wang et al., 2018; Badretdinov and Mudarisov, 2019; Badretdinov et al., 2019; Korn, 2020).

Wang et al. (2018) proposed a fatigue life analysis method and an optimization method for designing the cleaning system in order to improve the fatigue life of the cleaning system in combine harvesters. The resulting model of the cleaning system dynamics which was developed identified the key factors that affect the fatigue life of the main components of the cleaning device.

In their work, Korn and Herlitzius (2017) described the possibility of using a coupled CFD-DEM approach to simulate the process of separating grain from impurities in a cleaning device of a combine harvester. A strategic approach to create a reliable simulation model was needed to account for a large number of influencing factors, their interactions, a wide range of scattering of properties of the biogenic particles, and the resulting complexity of the separation process. Numerical results have shown the applicability of the numerical method by comparing it with similar experiments. However, potential deviations were noted, which underscore the need for further research to improve parameterization and modeling (Korn and Herlitzius, 2017; Korn, 2020).

Ostrikov et al. $(2018,2020)$ investigated the relationship between the cleaning effect of a combine harvester's cleaning system and its influencing factors. A model was developed based on the rate of cleaning losses and the parameters of the clean system. The results were checked to measure the cleaning efficiency of 
each group under various combinations of conditions. We analyzed the direct or indirect relationship between the rate of cleaning losses and the parameters in the experiment for each operating state. Based on the experimental data obtained, the rate of losses was predicted for several sets of factors.

Mirzazadeh et al. (2015) carried out experimental research on a grain harvester cleaning system mock-up with various design and technological parameters (grain supply, fan speed, sieve gaps).

In the $\mathrm{GH}$ cleaning system, the technological process of airsieve separation of the grain heap from impurities can be mathematically described as a complex system of polydisperse twophase flow, taking into account the forces of gravity, friction, and inertia. One phase is the fan airflow, while the other involves the solid particles (elements of the grain heap). In particular, particles can have different concentrations and physical and mechanical properties (mass, density, geometric dimensions, moisture, elasticity, wind resistance, etc.). The differences between the phases determine the nature of the interaction between the airflow and particles. Also, the inertia and windiness of particles (dense-seeds, light-chaff, chaff) make them follow different trajectories. Due to aerodynamic drag force, light particles are separated by the airflow, which is stronger than the force of gravity, due to the difference between the air speed and the the speed of the hovering particles. The grains (with more massive particles) are predominantly moved (separated from lighter particles) due to the action of gravity and inertia of the sieves, while the aerodynamic drag force has no significant action (Kutzbach and Quick, 1999; Kutzbach, 2001; Rademacher, 2003; Feiffer et al., 2005; Kelemen et al., 2005; Miu and Kutzbach, 2008; Steponavičius et al., 2008; Voicu et al., 2008; FAO Report, 2014; Mirzazadeh et al., 2015; Špokas et al., 2016; Korn and Herlitzius, 2017; Aldoshin and Lylin, 2018; Wang et al., 2018; Badretdinov et al., 2019; Ospanov et al., 2019; Korn, 2020).

\section{Materials and methods}

\section{Formulation of the problem}

Today, unfortunately, harvesting operations are performed without taking into account agrotechnical requirements, with significant losses of the harvested crop (Figure 1) and, therefore, high costs. For an accurate mathematical description of the GH purification system technological process, it is necessary to identify the presence and intensity of exchanges between the phases (gas - particles), particle concentration, etc. Thefore, it is necessary to establish the mode of interaction between the air and the grain heap using Reynolds number of the Rep particle, the volume concentration of particles Q, and the design and technical parameters of the cleaning system. In turn, in order to determine these parameters, it is necessary to know the amount of material to be cleaned (throughput), the speed of the airflow and particles, as well as the coefficients of their aerodynamic resistance (Korn and Herlitzius, 2017; Wang et al., 2018; Badretdinov et al., 2019; Korn, 2020).

\section{Determination of the air-grain heap flow class in the cleaning system of a combine harvester}

Air-screen systems for separating grains from impurities are widely used in combine harvesters. For the mathematical description of the cleaning system technological process in a combine harvester, we represent the airflow as gas and the grain heap as solid particles and further describe their joint movement as a heterogeneous polydisperse flow. This flow is polydisperse and heterogeneous because the grain heap is heterogeneous too, since it contains solid particles (pure grain and weeds) with different physical and mechanical geometric parameters. For an accurate mathematical description of this flow, it is necessary to determine the class of the air-grain mixture flow.

The concentration of particles in polydisperse heterogeneous flows is an extensive physical characteristic. Dispersed phase concentrations are divided into mass, volume, and counting.

The interaction of the airflow with solid particles (grain heap) is characterized by a relatively small volumetric content of grain heap particles. The total mass of all particles is much higher than the mass of the airflow itself. The mass concentration of particles for such flows, where the mass of particles is more massive than the mass of the airflow, practically does not change with an increase in the dispersed phase, content but it tends asymptotically to unity. Therefore, the mass concentration $(W)$ of the grain heap

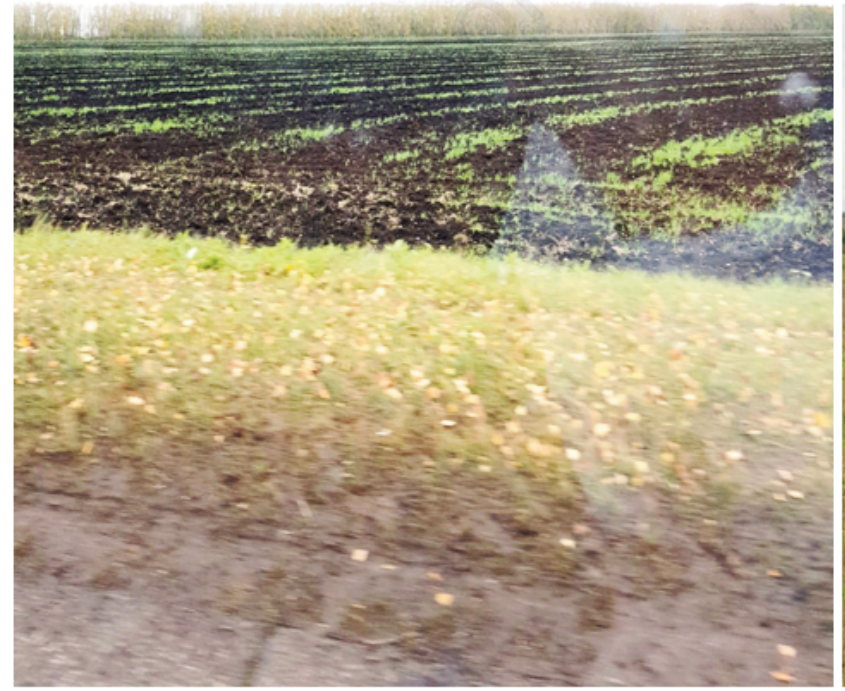

$\mathbf{A}$

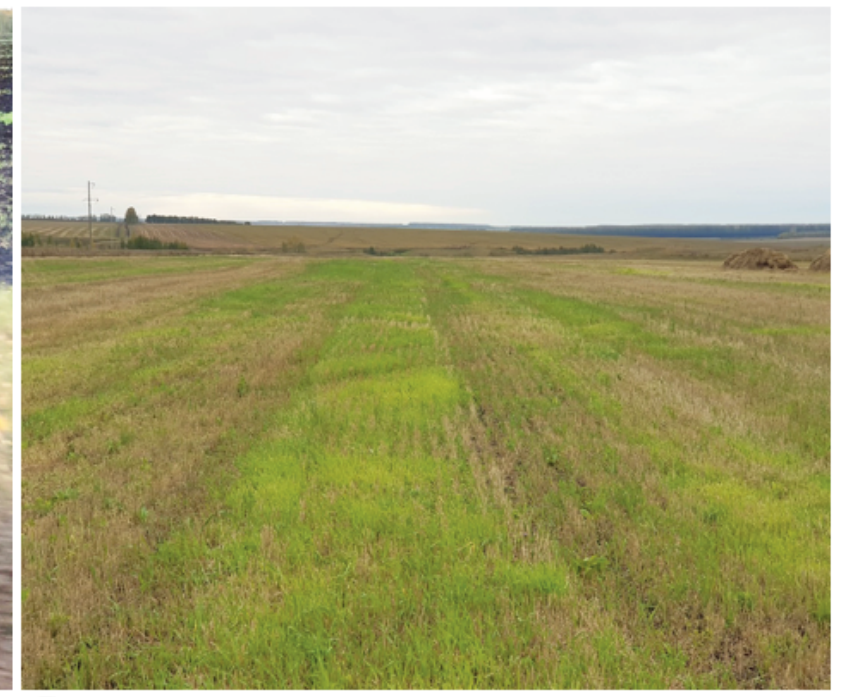

B

Figure 1. A) Plowed field after harvesting grain (green stripes - losses behind the combine harvester); arge losses after harvesting. 
particles can be calculated using the expression:

$W=\frac{Q \cdot \rho_{p}}{\rho}$,

The volumetric $Q$ and the counting $K$ concentration of the grain heap particles can be expressed as:

$Q=\frac{K \cdot p \cdot d^{3} p}{6}$

where $K$ is the counting concentration of particles (the number of polydisperse solid particles of the grain heap per unit volume in the cleaning system), $\mathrm{pcs} / \mathrm{m}^{3} ; \rho$ is air density, $\mathrm{kg} / \mathrm{m}^{3} ; \rho_{p}$ - density of solid particles (grain), $\mathrm{kg} / \mathrm{m}^{3} ; d_{p}$ - equivalent diameter of solid particles, $\mathrm{m}$.

To determine the type of flow in a combine harvester cleaning system during experimental studies of polydisperse heterogeneous flows, the volume $Q$ and mass $W$ consumption concentration can be determined as follows (Aldoshin and Lylin, 2018; Borodin and Zhangabay, 2019).

$Q_{G}=\frac{Q_{V p}}{Q_{V g}}$,

$W_{G}=\frac{W_{M p}}{W_{M g}}$,

where $\left(Q_{V p}, Q_{V g}\right)$ are volumetric and $\left(W_{M p}, W_{M g}\right)$ are mass flow rates of grain heap particles and airflow through the platform $S$ (surface area of the sieve mill of the cleaning system of the combine harvester):
$G_{V p}=K \cdot \frac{p \cdot d^{3} p}{6} \cdot V \cdot S=K \cdot Q_{b} \cdot V \cdot S$,

$G_{V p}=U \cdot S$,

$G_{M p}=K \cdot \rho_{p} \cdot \frac{p \cdot d^{3} p}{6} \cdot V \cdot S=K \cdot \rho_{p} \cdot Q_{B} \cdot V \cdot S=K \cdot m_{p} \cdot V \cdot S$,

$G_{M g}=\rho \cdot U \cdot S$,

where $V$ is the speed of the grain heap, $\mathrm{m} / \mathrm{s}$;

$U$ is the airflow speed, $\mathrm{m} / \mathrm{s}$;

$S$ is the surface area of the sieve of the cleaning system, $\mathrm{m}^{2}$;

$Q_{b}$ - is the volume of the grain heap, $\mathrm{m}^{3}$;

$m_{p}$ is the mass of the grain heap, $\mathrm{kg}$.

It is necessary to know the throughput $q(\mathrm{~kg} / \mathrm{s})$ or the productivity $q_{M}(\mathrm{t} / \mathrm{h})$ of the combined harvester cleaning system, i.e., separation of the grain heap per unit of time in order to calculate the volumetric flow rate of grain heap particles (the volume of particles in an elementary flow volume).

The throughput of the number of particles per unit of time $q_{p s c}$ (pcs/s), taking into account the mass of 1000 pieces of grain material $m_{1000}$, is determined as follows:

$q_{p c s}=\frac{q \cdot 1000}{m_{1000}}$,

This formula calculates the counting concentration of the grain heap $\left(\mathrm{pcs} / \mathrm{m}^{3}\right)$ :

$K=\frac{q_{p c s}}{V \cdot S}$

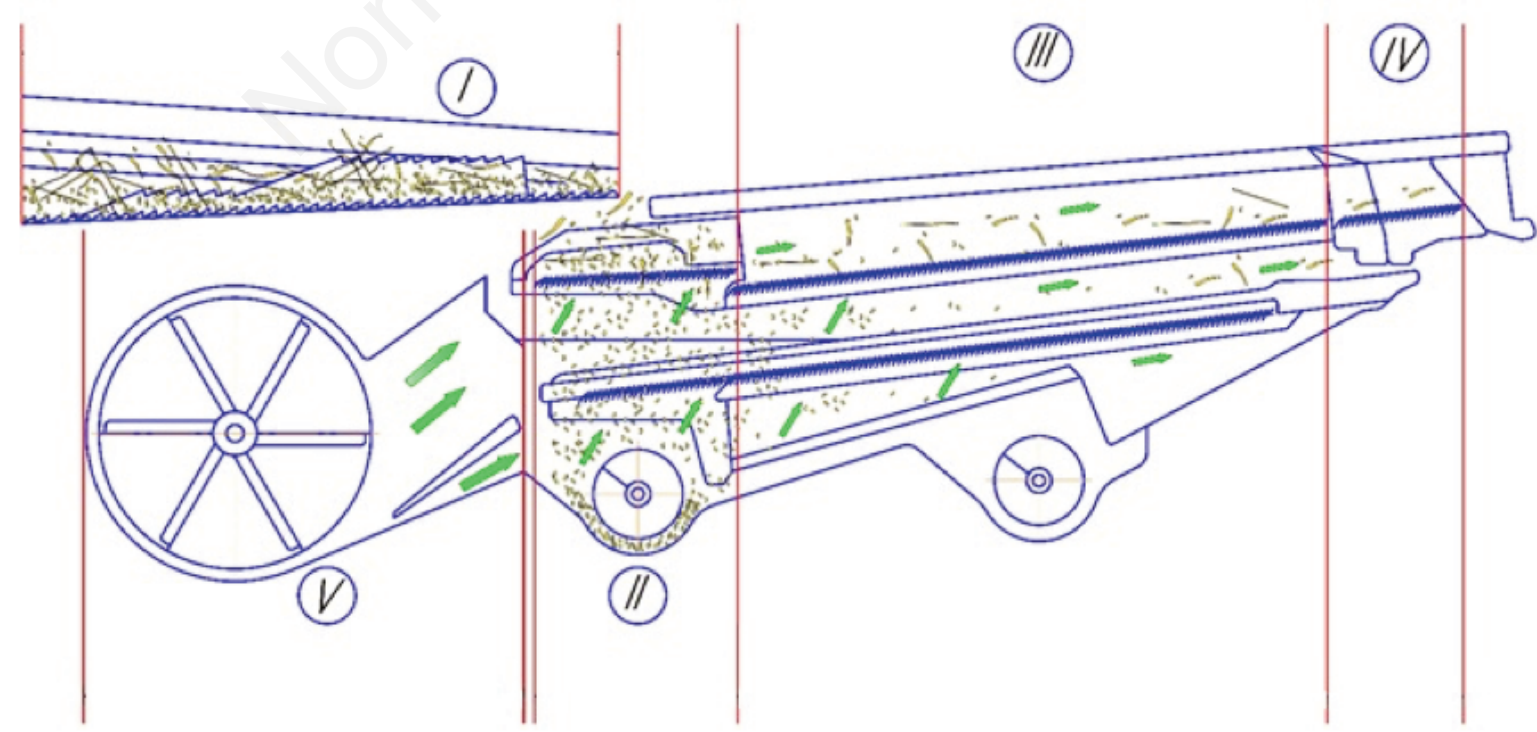

Figure 2. The division into sections (I-V) to determine the concentrations ( $Q$ and $W$ ) in the combine harvester cleaning system. 
Considering formula (6) into formula (5) and supplying formula (10), the formula (2) for determing the volume concentration will be written in the final formula:

$Q=\frac{q_{p c s} \cdot p \cdot d^{3} p}{6 \cdot U \cdot S}=\frac{q_{p c s} \cdot Q_{b}}{U \cdot S}$,

The mass concentration of a grain heap in the cleaning system of a combine harvester supplying to expression (1) taking into account (11) is determined:

$W=\frac{q_{p c s} \cdot Q_{b} \cdot \rho_{p}}{U \cdot S \cdot \rho}=\frac{q_{p c s} \cdot m_{p}}{U \cdot S \cdot \rho}$,

Figure 2 shows the division into sections to calculate concentrations $(\mathrm{Q}$ and $\mathrm{W})$ in the cleaning system of a combine harvester.

The volume $(Q)$ and mass $(W)$ concentrations of the grain heap were calculated in the II-IV sections taking into account the yield $(Y)$ from 10 to $40 \mathrm{c} / \mathrm{ha}$ and the speed $(s)$ of the combine (combine $5 \mathrm{~km} / \mathrm{h}$ ), (Figure 2) in the cleaning system of the combine harvester. This data is reported in Table 1.

A surface graph can be derived from the calculated values of the volumetric concentration $(Q)$ of the grain heap, taking into account the yield $(Y)$ and speed $(s)$ of the combine (Figure 3 ).

With an insignificant volumetric concentration $\left(Q \leq 10^{-6}\right)$ of a dispersed impurity, its time-averaged effect on the carrier medium flow is negligible. In this type of heterogeneous flows, the key factor is the influence of the carrier phase on the particles. This determis ultimately all their characteristics (averaged and pulsation velocities, local concentration, etc.) with an increase in the volumetric content $\left(10^{-6}<Q \leq 10^{-3}\right)$, while the particles, in turn, begin to influence the carrier gas in a reverse pattern. These two types of heterogeneous flows are often referred to as low-dust flows. In a highly dusty flow $\left(Q>10^{-3}\right)$, in addition to the existing interactions between the particles and the carrier phase, the particles begin to interact with each other.

In the grain cleaning system, the grain heap volume concentration varies within $Q \approx 10^{-7} \div 10^{-3}$ and directly depends on the yield. According to the accepted classification, this refers to heterogeneous flows. In this case, the airflow affects the movement of particles, and the reverse effect on the airflow is negligible.

The most suitable method to describe the process of interaction of the airflow with a grain heap in a combine harvester cleaning system is in our opinion a mathematical model of a polydisperse heterogeneous two-phase gas flow with particles, described by the trajectory (Lagrangian) approach. Mathematical modeling takes into account the volumetric concentration of grain heap, Reynolds number of particles, the physical properties of airflow, the physical and mechanical parameters of the grain heap, as well as the speed of the phases.

The mathematical description of the air-grain heap flow is based on some assumptions and simplifications associated with the mathematical approximation and description of physical parameters and processes. These assumptions and simplifications must be observed and performed with absolute accuracy in the mathematical modeling of the separation of a grain heap by airflow in the cleaning system of a combine harvester.

One of the possible ways to increase the separation efficiency of air-sieve cleaning could be the creation of fresh air flows in their chamber. The structure of air flows and the distribution of their speeds above sieves depend on the fan and air duct design.

The task is to assess the rational parameters of the deflectors and the centrifugal fan operating modes to optimize the air flows in the fan throat, ensuring their high-quality distribution over the sieves of the air-sieve cleaning of the combine harvester.

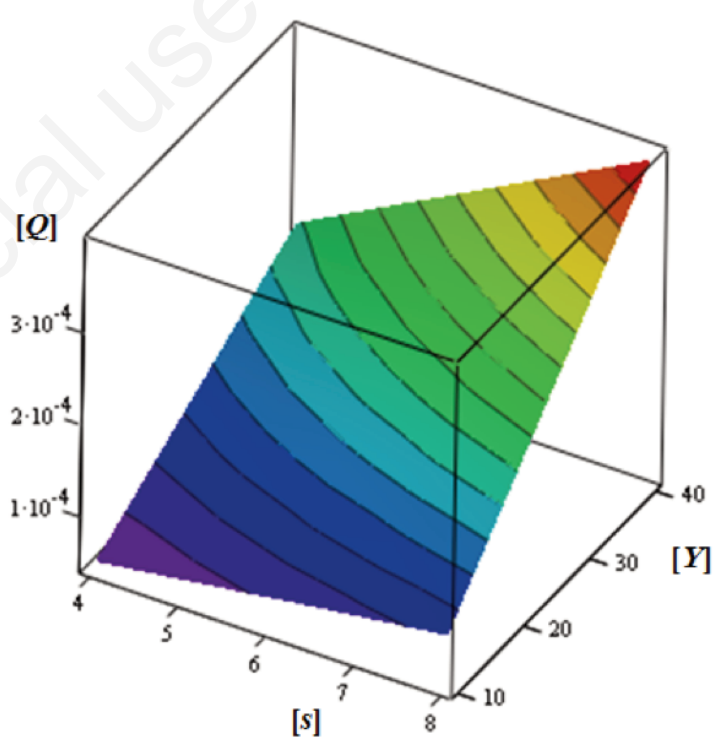

Figure 3. Graph showing that the surface of volumetric concentration depends on the combine speed and crop yield.

Table 1. Calculated data of changes in volume and mass concentrations in the cleaning system depending on yield (at a grain harvesters speed of $5 \mathrm{~km} / \mathrm{h})$.

\begin{tabular}{|c|c|c|c|c|c|c|}
\hline \multirow[t]{2}{*}{ Yield $(Y)$ [centner per hectare] } & \multicolumn{3}{|c|}{ Volume concentration (Q) } & \multicolumn{3}{|c|}{ Mass concentration $(W)$} \\
\hline & II & III & IV & II & III & IV \\
\hline 10 & 0.000061 & 0.000055 & 0.000008 & 0.07 & 0.06 & 0.01 \\
\hline 15 & 0.000092 & 0.000082 & 0.000012 & 0.10 & 0.09 & 0.01 \\
\hline 20 & 0.000123 & 0.000110 & 0.000016 & 0.14 & 0.12 & 0.02 \\
\hline 25 & 0.000154 & 0.000137 & 0.000020 & 0.17 & 0.15 & 0.02 \\
\hline 30 & 0.000185 & 0.000165 & 0.000025 & 0.21 & 0.18 & 0.03 \\
\hline 35 & 0.000216 & 0.000192 & 0.000029 & 0.24 & 0.22 & 0.03 \\
\hline 40 & 0.000247 & 0.00022 & 0.000033 & 0.28 & 0.25 & 0.04 \\
\hline
\end{tabular}


Research method: studies of fans of various designs on a mock-up of an air-sieve cleaning system of a combine harvester, multivariate analysis, modeling of the airflow at the outlet of the blower discharge channel, and their subsequent distribution over the sieves.

The irregularity of the airflow along the width of the channel of the air-sieve part of the combined harvester cleaning system contributes to the need to reduce the airflow rate in the sieve area (to reduce grain losses after cleaning). It reduces the process of separating small particles and affects the quality of their separation.

A model was developed for the study and calculation of the work process, the distribution of airflow created by the fan of the GH cleaning system. Based on the 3D model (Figure 4), using the boundary conditions Slip wall in a rotating coordinate system, a calculation was made in the FlowVision software package (3.10.01) (Mudarisov and Badretdinov, 2013; Badretdinov et al., 2019).

\section{Results}

\section{Results of the numerical implementation of the devel- oped model and substantiation of the design and tech- nical parameters of the fan}

The fan design and technical parameters were substantiated in the FlowVision software package based on the condition of ensuring the airflow rate uniformity at the outlet of the discharge channel along with the diagram of fan speeds and performance. Some fan design parameters, such as shape of impeller blades, number and angle of inclination of blades, and the fan impeller diameter, are considered (Figure 5) (Mudarisov and Badretdinov, 2013; Badretdinov et al., 2019). As can be seen, at the exit of the fan, there are an uneven distribution of the airflow along the width of the outlet channel, and, therefore, a fairly low quality cleaning of the grain heap and grain loss.

Figure 6 shows that the distribution of the airflow rate across the discharge channel width at the outlet of the fan is uneven. The center is the maximum airflow rate, and the edges correspond to the minimum airflow rates (Table 2).

It can be seen that the airflow rate becomes more uneven at the outlet of the discharge channel, when the fan speed increases, as evidenced by the dispersion values. There is also a substantial deviation from the minimum to the maximum value of the airflow rate (unevenness is more than 19\%).

It is necessary to calculate their aerodynamic performance based on modeling the geometric surface to improve work quality indicators. By optimizing the geometric shape of the fan wheel blades, the aerodynamic performance is improved. It is possible to achieve a uniform distribution of the airflow, which will positively affect the processed material quality with no losses (Badretdinov and Mudarisov, 2019).

The concentrations obtained experimentally are used in machine modeling of the technological process of the GH cleaning system operation in the FlowVision program.

Here is the visualization of the airflow velocity trajectories obtained from the results of modeling and calculations in the FlowVision software package (Figure 7).

Figure 7 shows that the airflow generated by the fan passes through two sieve pans. The central part of the airflow is directed towards the upper screening box, while a small part of it is cut off by the airflow guide and directed towards the lower screening box, where airflow speed is lower (up to $3 \mathrm{~m} / \mathrm{s}$ ) than the airflow directed towards the upper screening box. In the front part of the upper sieve mill ( $1 / 3$ of the surface), the airflow speed is much higher (up to $9 \mathrm{~m} / \mathrm{s}$ ) than on the remaining surface of the sieve mill and amounts to 5 .. $6 \mathrm{~m} / \mathrm{s}$ (Figures 8 and 9; Table 3) (Badretdinov and Mudarisov, 2019).

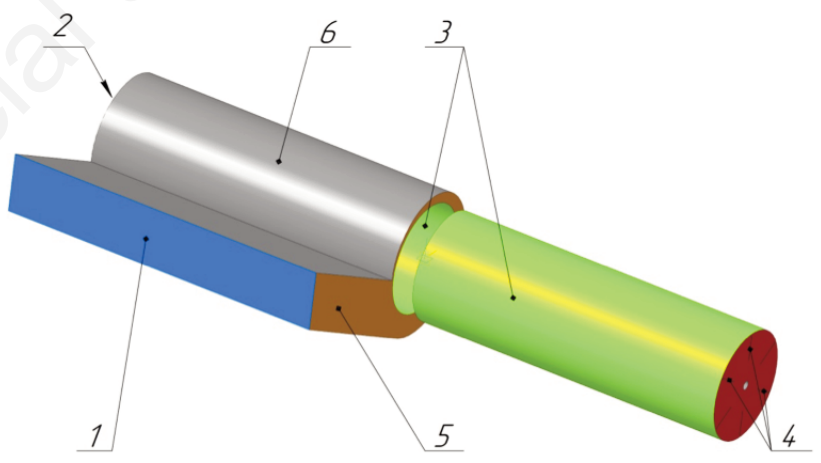

Figure 4. 3D-model of the fan of the grain harvesters cleaning system. Boundary conditions: 1 - airflow exit from the discharge channel; 2 - inlet window of the airflow; 3 - wall with slippage (outer diameter of the fan impeller); 4 - rotating mesh (fan blades); 5, 6 - wall of the fan case.

Table 2. Results from the calculation of the fan of the existing design of the grain harvesters at different fan speeds.

\begin{tabular}{|c|c|c|c|c|c|c|}
\hline \multirow{2}{*}{ Fan speed [rpm] } & \multirow[b]{2}{*}{ Min } & & \multicolumn{3}{|c|}{ Outlet airflow speed [m/s] } & \multirow[b]{2}{*}{ Variation, \% } \\
\hline & & Max & Average value & Dispersion & The average square of switching off & \\
\hline 400 & 4.21 & 8.18 & 6.91 & 1.79 & 1.34 & 19.35 \\
\hline 450 & 4.74 & 9.22 & 7.82 & 2.25 & 1.50 & 19.18 \\
\hline 500 & 5.10 & 10.02 & 8.47 & 2.73 & 1.65 & 19.51 \\
\hline 600 & 6.19 & 12.24 & 10.35 & 3.98 & 2.00 & 19.27 \\
\hline 650 & 6.78 & 13.16 & 11.17 & 4.56 & 2.14 & 19.13 \\
\hline 700 & 7.30 & 14.37 & 12.23 & 5.43 & 2.33 & 19.05 \\
\hline 800 & 8.51 & 16.46 & 13.99 & 6.91 & 2.63 & 18.79 \\
\hline 850 & 8.66 & 17.35 & 14.73 & 8.15 & 2.85 & 19.38 \\
\hline
\end{tabular}


Statistical data of the airflow velocity distribution (coefficient of variation) along the width and the length of the upper sieve were determined (Figure 10) under experimental production conditions for combine harvesters (Acros, John Deere, Case, New Holland). The air velocity was measured with a KIMO digital anemometer (Badretdinov and Mudarisov, 2019).

Figure 10 show that the airflow is unevenly distributed over the entire area of the sieve, apart from the beginning and end of the sieve where it is more evenly distributed. A substantial scatter is observed in the middle part of the sieve mill. Due to a substantial range of airflow rate scattering in this section, the technological process of pneumatic sieve cleaning of the grain heap may be disrupted. Thus, light impurities can get into the cleaned grain material. The opposite picture is observed along the sieve width. In the middle of the sieve, there is a more even airflow, while uniformity is discontinued at edges.

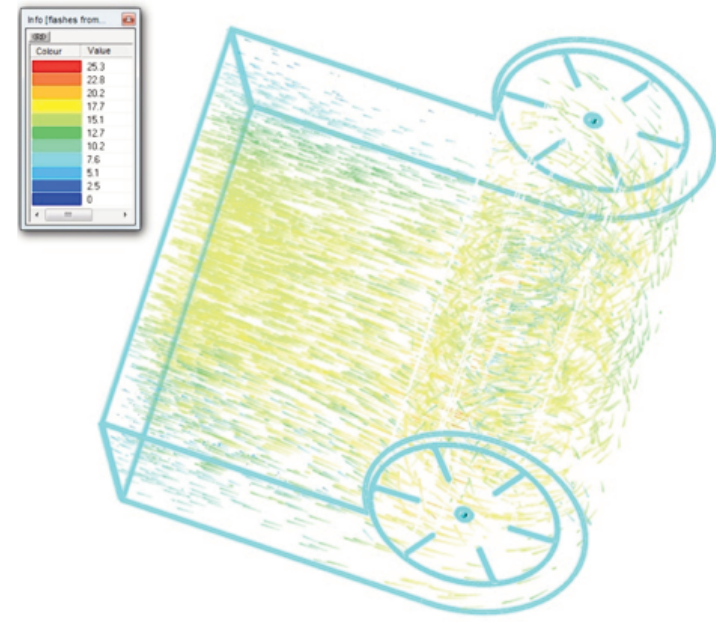

$\mathbf{A}$

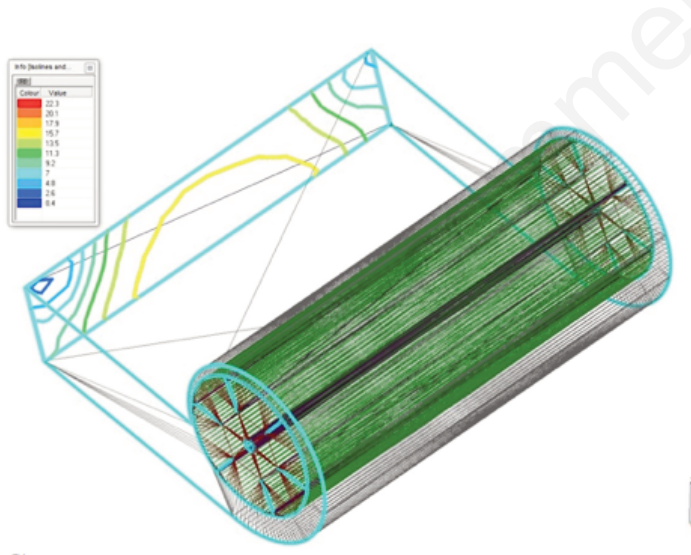

C

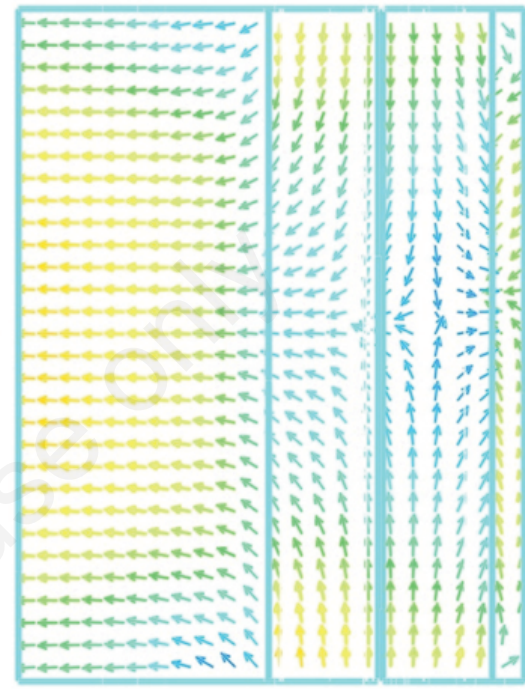

B

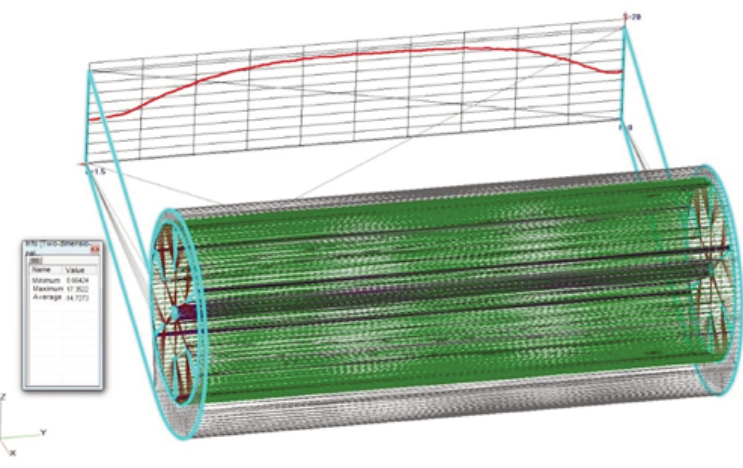

D

Figure 5. A) Model for calculating the fan airflow on the existing designs of the grain harvesters (GH) cleaning system (bursts of airflow speed); B) calculating the fan airflow on the existing designs of the GH cleaning system (velocity vector) top view; C) the results from the calculation of the airflow at the outlet of the blower discharge channel on the GH cleaning system (isolates of the airflow velocity distribution); D) the results from the calculation of the airflow at the outlet of the blower discharge channel on the GH cleaning system (diagram of the distribution of the airflow rate).

Table 3. Statistical analysis of the distribution of: i) airflow velocity over the upper sieve bed grain harvesters (GH) (standard) along its length; ii) airflow rate distribution at the outlet of the fan GH pressure channel (with deflectors); and iii) airflow speed distribution over the upper sieve mill GH (with deflectors).

\begin{tabular}{lcccccc} 
Parameter $($ speed, $\mathrm{m} / \mathrm{s})$ & Min & Max & The average value, $X$ & Dispersion, $\sigma^{2}$ & The average square of switching off, $\sigma \quad$ Variation, $v$ \\
Airflow velocity & 3.75 & 10.29 & 6.87 & 3.75 & 1.94 & 28.20 \\
Airflow rate distribution & 12.60 & 16.34 & 14.93 & 1.44 & 1.20 & 8.03 \\
\hline Airflow speed distribution & 3.72 & 4.21 & 3.96 & 0.03 & 0.17 & 4.32 \\
\hline
\end{tabular}


Table 4 shows a comparative analysis of the statistical data measuring the airflow rate on the sieves of a New Holland TX-65 combine harvester and with New Holland TX-65 deflectors installed.

According to the variation values (Table 4), New Holland TX65 combine harvester with installed deflectors had a significantly reduced airflow distribution across the width of the sieve mill from $(23 \div 67)$ to $(9 \div 24) \%$.

Combine harvester New Holland TX-65 with installed deflectors in the discharge channel of the cleaning system was used to harvest rapeseeds, Yubileinaya variety (direct combining) under the conditions of the Bashkir State Agrarian University Study field at Dmitrievka village, Ufa region in the Republic of Bashkortostan.

Figure 11 shows the sampling during the harvesting of the rapeseed crop, Yubileinaya variety, in the same field and during the same combine harvester operation. Samples were taken from the bunker of a New Holland TX-65 combine harvester.

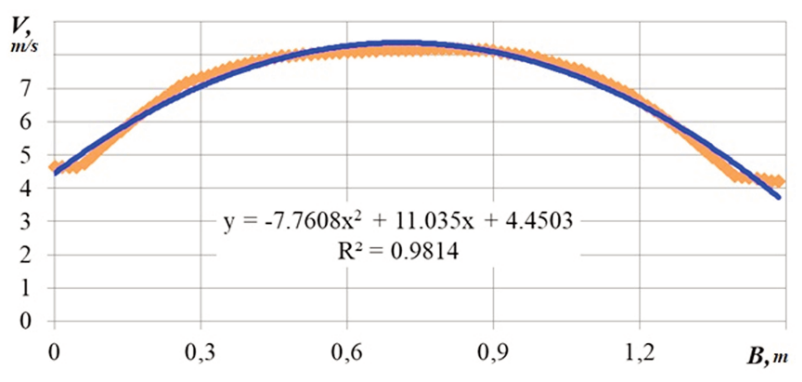

Figure 6. The results from the calculation of airflow at the outlet from the discharge channel (along the fan width) on the existing structures of the grain harvesters cleaning system.

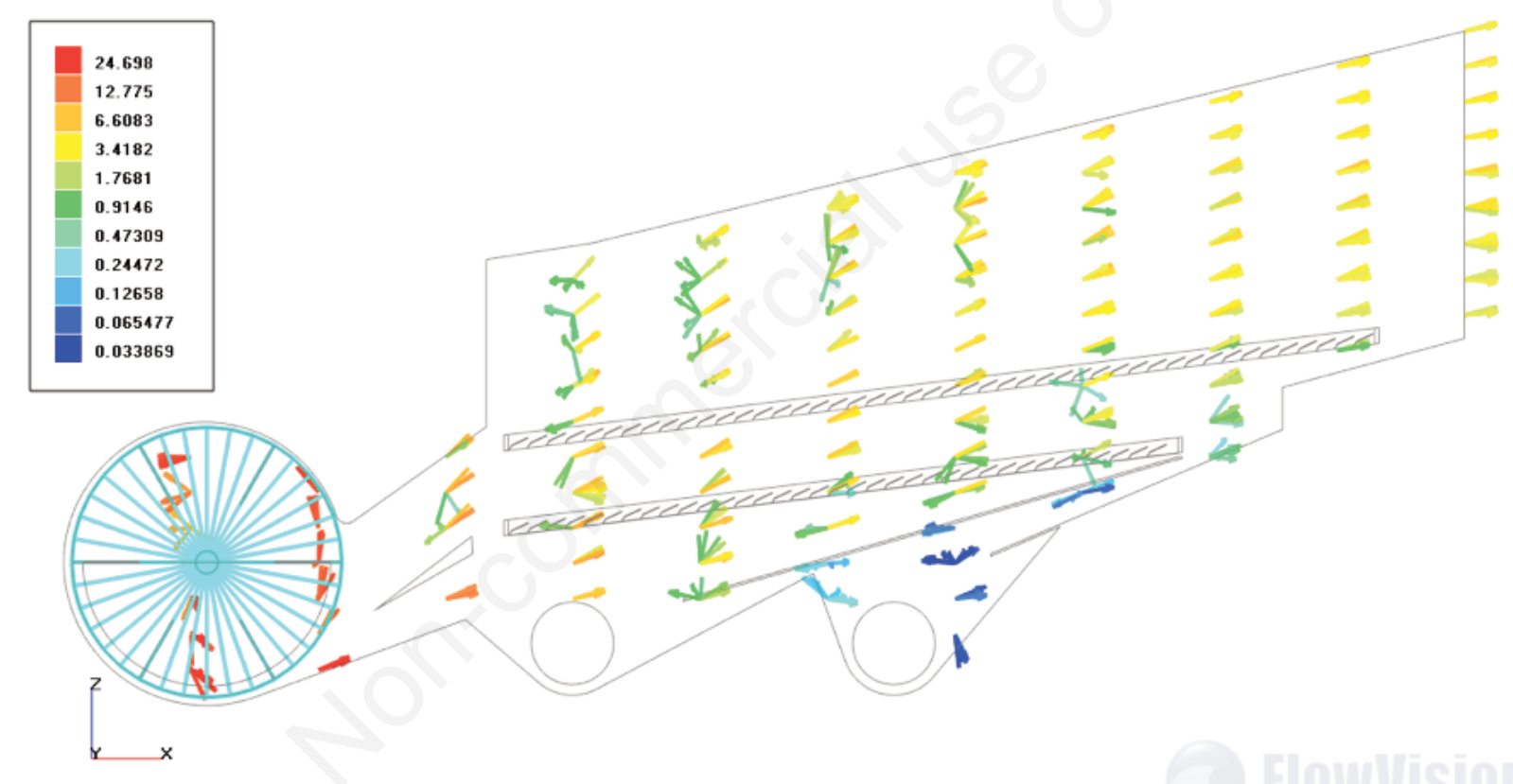

Figure 7. Trajectories of airflow velocity vectors.

Table 4. Statistical analysis of the change in the air flow rate on the sieves of the New Holland TX-65 combine harvester along the sieve width.

\begin{tabular}{|c|c|c|c|c|c|}
\hline Sieve width & 1 & 2 & 3 & 4 & 5 \\
\hline $\begin{array}{l}\text { Without deflectors } \\
\text { Average value, } \mathrm{m} / \mathrm{s} \\
\text { Dispersion } \\
\text { Average square of switching off } \\
\text { Variation, } \%\end{array}$ & $\begin{array}{c}1.19 \\
0.08 \\
0.28 \\
23.12\end{array}$ & $\begin{array}{c}1.41 \\
0.20 \\
0.45 \\
31.84\end{array}$ & $\begin{array}{c}1.23 \\
0.69 \\
0.83 \\
67.51\end{array}$ & $\begin{array}{c}1.47 \\
0.35 \\
0.59 \\
40.00\end{array}$ & $\begin{array}{c}1.20 \\
0.28 \\
0.53 \\
44.10\end{array}$ \\
\hline $\begin{array}{l}\text { With deflectors } \\
\text { Average value, } \mathrm{m} / \mathrm{s} \\
\text { Dispersion } \\
\text { Average square of switching off } \\
\text { Variation, } \%\end{array}$ & $\begin{array}{c}1.58 \\
0.08 \\
0.28 \\
17.99\end{array}$ & $\begin{array}{c}1.37 \\
0.06 \\
0.24 \\
17.66\end{array}$ & $\begin{array}{l}1.84 \\
0.03 \\
0.17 \\
9.25\end{array}$ & $\begin{array}{c}1.38 \\
0.04 \\
0.19 \\
13.82\end{array}$ & $\begin{array}{c}1.54 \\
0.14 \\
0.37 \\
23.97\end{array}$ \\
\hline
\end{tabular}




\section{Discussion}

Experimental data on the distribution of the airflow rate over the entire sieve area of existing modern GH showed that the airflow is distributed unevenly over the sieve area and has a wide range of variations. The results of other evidence obtained by researchers (Alferov, 1987; Kutzbach, 2001; Miu and Kutzbach, 2008; Steponavičius et al., 2008; Kotov and Chaus, 2010; Mudarisov and Badretdinov, 2013; Vasilevskij et al., 2013; Mirzazadeh et al., 2015; Baran et al., 2016; Špokas et al., 2016; Korn and Herlitzius, 2017; Sorochenko, 2017; Aldoshin and Lylin, 2018; Badretdinov and Mudarisov, 2019; Korn, 2020) indicates that the technological process of pneumo-sieve cleaning in the GH violates agrotechnical requirements (Špokas et al., 2016; Aldoshin and Lylin, 2018; Wang et al., 2018; Badretdinov et al., 2019). Due to the increase in productivity (Miu and Kutzbach, 2008; Aldoshin and Lylin, 2018; Badretdinov and Mudarisov, 2019) and throughput (Špokas et al., 2016; Badretdinov and Mudarisov, 2019), problems arise in terms of quality of the purification system function- ing. This can be explained by the complexity of the simultaneous regulation of some design and technological parameters (fan speed and airflow rate, sieve gaps, and angular speed of the sieve drive crank) (Mirzazadeh et al., 2015; Wang et al., 2018) and depends on the harvested crop and on its physical and mechanical properties (geometric parameters, humidity, contamination) (Kutzbach and Quick, 1999; Kutzbach, 2001; Feiffer et al., 2005; Kelemen et al., 2005; Steponavičius et al., 2008; FAO Report, 2014; Špokas et al., 2016).

The experimental data were confirmed by theoretical studies (Baran et al., 2016; Badretdinov et al., 2017; Sorochenko, 2017; Badretdinov and Mudarisov, 2019) on the mathematical description and modeling of a polydisperse two-phase flow, taking into account concentration, inertia, relaxation time, drag coefficient (Korn, 2020). Similar studies were carried out by other scientists, which are reflected in Korn and Herlitzius's (2017) works and investigated the possibility of using a coupled CFD-DEM approach to simulate separating grain from impurities in a cleaning device of a combine harvester.

A

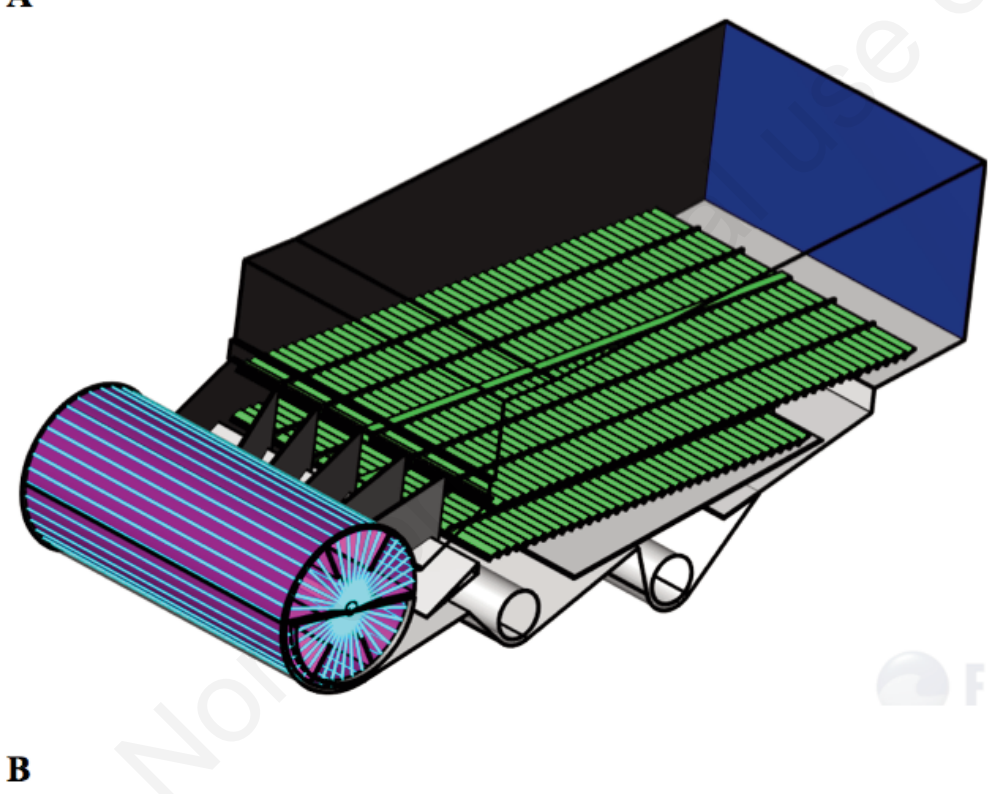

B

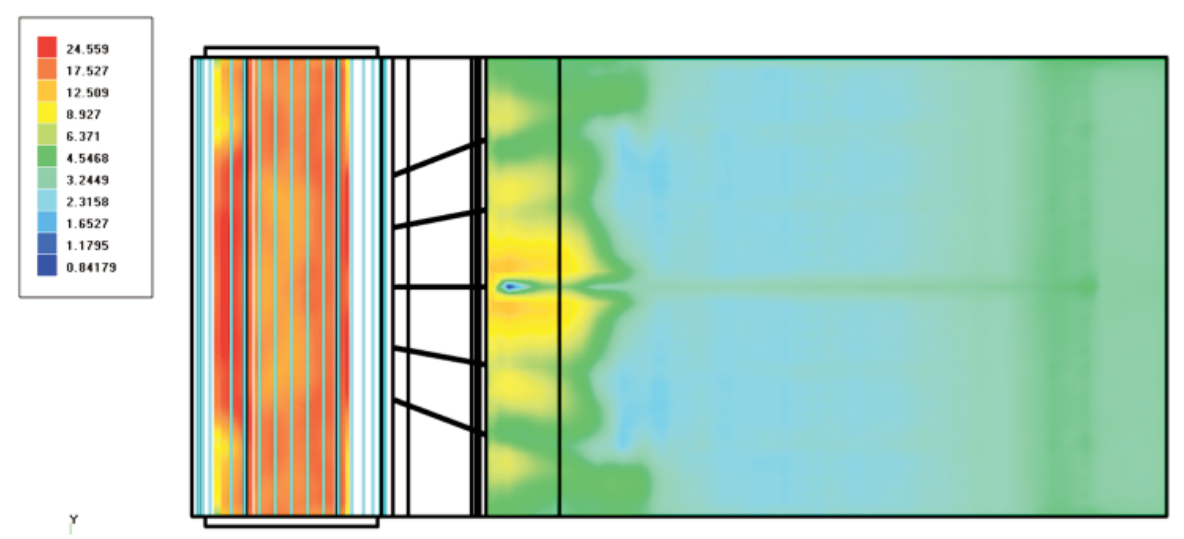

Figure 8. A) Calculated 3D model of the grain harvesters cleaning system with installed deflectors in the blower discharge channel; B) the results from the calculation of the airflow rate distribution over the sieve (filling). 
A comparative analysis of theoretical and experimental studies showed that the reliability is more than 0.95 according to the Student's t-test, which gives reasons to believe that the results can be accepted as reliable.

Some problem areas of the treatment system were identified having simulated and calculated a model of real GH (Miu and Kutzbach, 2008; Voicu et al., 2008; Ermoliev and Muratov, 2011; Mirenko et al., 2011; Baran et al., 2016; Korn and Herlitzius, 2017; Sorochenko, 2017; Badretdinov et al., 2019) using this method. These problems could be solved by changing the design parameters and adding deflectors to the fan discharge channel (patent RU $2621026 \mathrm{C} 1$ and RUS 175203), which contributes to a more uniform distribution of the airflow along the width of the channel, and then over the entire area of the GH sieve.

On the basis of the characteristics obtained it is possible to develop recommendations for optimizing the fan design and technical parameters and the cleaning system of the combine harvester as a whole.

The application of this modeling method opens up the possibility of improving the cleaning systems of combine harvesters without high costs and efforts (Badretdinov and Mudarisov, 2019).

A

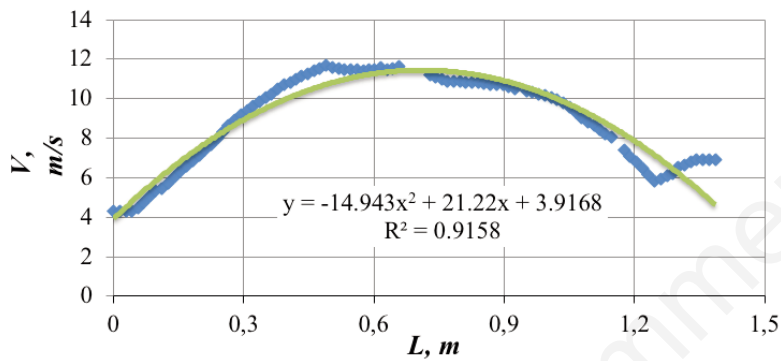

B

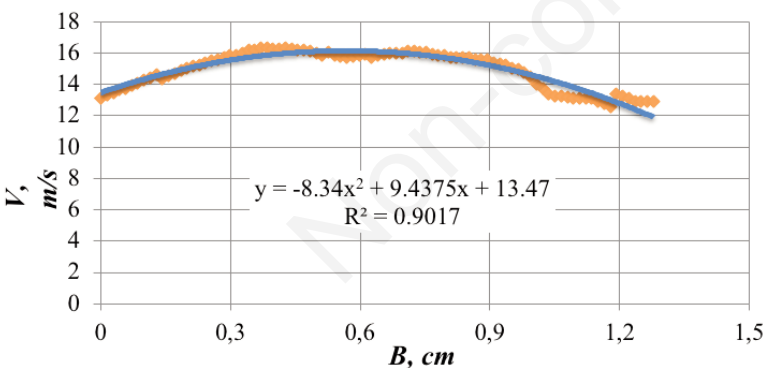

C

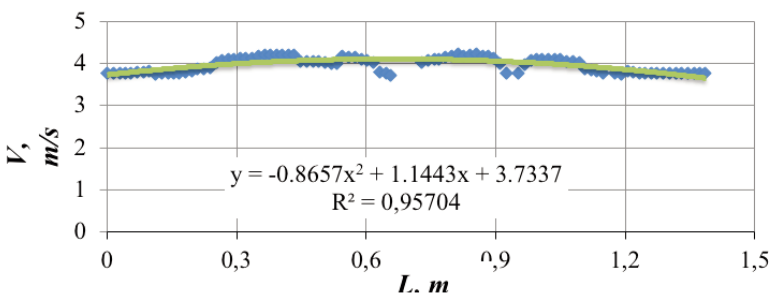

Figure 9. A) Diagram of the airflow speed distribution over the surface of the upper sieve bed grain harvesters (GH) (standard) along the length; $B$ ) diagram of the airflow rate distribution at the outlet of the fan $\mathrm{GH}$ pressure channel (with deflectors); $\mathrm{C}$ ) diagram of the airflow speed distribution over the surface of the upper sieve bed GH (with deflectors) along the length.
The proposed modernization of the cleaning system design is universal and can be installed on any combined harvester cleaning system. Modernization of the cleaning system design, namely the installation of deflectors in the cleaning system blower channel allows the airflow to be evenly distributed in the sieves and better quality with no losses to carry out air-sieve cleaning of the grain heap.
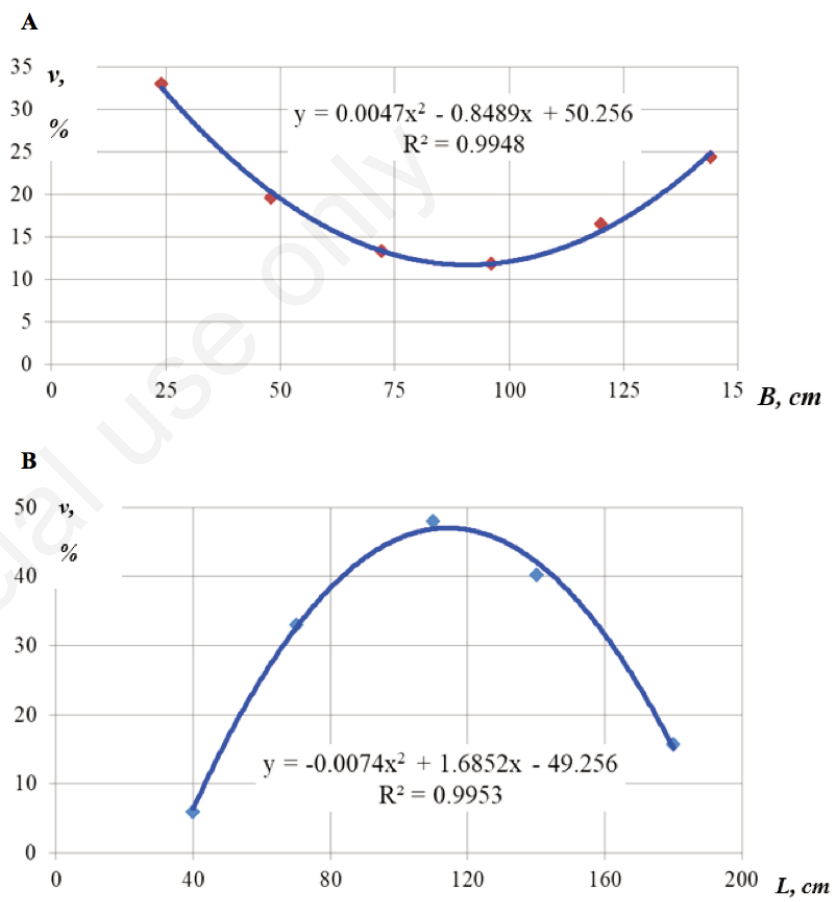

Figure 10. A) Diagram of the distribution of the airflow velocity coefficient of variation $v$ along the width $B$ on the grain harvesters (GH) sieve surface; B) graph of the distribution of the airflow velocity coefficient of variation $v$ along the $L$ on the surface of the GH sieve.

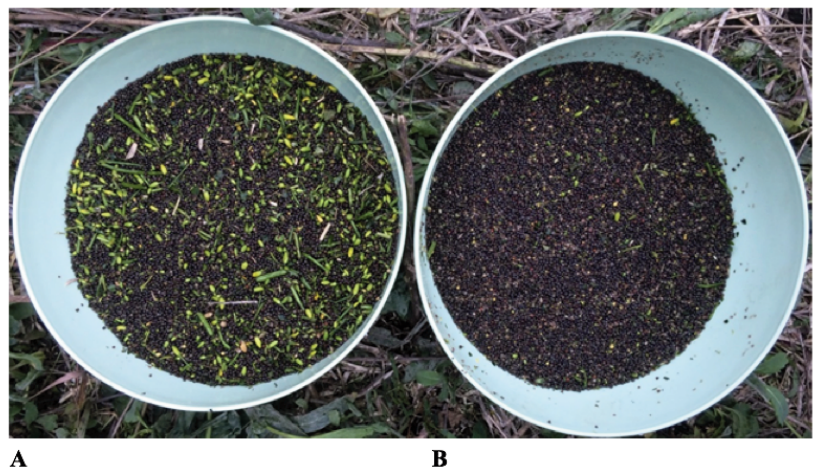

Figure 11. Sampling during harvesting of Yubileynaya rapeseed crop: A) existing structure; $B$ ) with deflectors. 


\section{Conclusions}

We determined the volumetric $\left(Q=8 \cdot 10^{-6} \div 2,5 \cdot 10^{-4}\right)$ and mass $(W=0.01 \div 0.3)$ concentrations of the grain heap in different sections of the sieve mill of the combine harvester cleaning system. The experimental measurements of the airflow velocity on the sieve mill surface for the existing designs of modern combine harvester cleaning system were $3.75 \div 10.2 \mathrm{~m} / \mathrm{s}$. The results were implemented in the mathematical model of a complete description of the technological process of a combined harvester cleaning system using a two-phase flow mechanics. The obtained parameters made it possible to use the methods of gas-particles two-phase flows for modeling the technological process of a combine harvester cleaning system.

\section{References}

Aldoshin N.V., Lylin N.A. 2018. Improving the design of the grain combine harvester cleaner. Russ. Agric. Sci. 44:108-11.

Alferov S.A. 1987. Air sieve cleaning of grain harvesters. Agropromizdat, Moscow, Russia.

Badretdinov I.D., Mudarisov S.G. 2019. Scientific substantiation and improvement of pneumatic systems of agricultural machines based on modeling the technological process. Vestnik NGIEI. 9:5-16.

Badretdinov I., Mudarisov S., Lukmanov R., Permyakov V., Ibragimov R., Nasyrov R. 2019. Mathematical modeling and research of the work of the grain combine harvester cleaning system. Comput. Electron. Agric. 165:104966.

Baran I.A., Popov V.B., Vyrskiy A.N., Trukhanovich S.V. 2016. Computer modeling of the process of separating grain and chaff into fractions in the cleaning system of a grain harvester. Vestnik GSTU im. P.O. Sukhoi. 3:3-9.

Borodin K., Zhangabay N.Z. 2019. Mechanical characteristics, as well as physical-and-chemical properties of the slag-filled concretes, and investigation of the predictive power of the metaheuristic approach. Curved Layer. Struct. 6:236-44.

Ermoliev Y.I, Muratov D.K. 2011. Modeling the process of centrifugal fans functioning in the air-screen cleaning of a grain harvester. Vestnik DSTU. 11:38-46.

FAO Report. 2014. Crop prospects and food situation; the Trade and Markets Division of FAO under the Global Information and Early Warning System. No. 4, December 2014. FAO, Rome, Italy.

Feiffer A., Feiffer P., Kutschenreiter W., Rademacher T. 2005. Getreideernte - sauber, sicher, schnell. DLG Verlag, Frankfurt, Germany.

Kelemen Z., Komladi J., Peto V. 2005. Der Verlauf der Durchsatzleistung, der Kornverluste und des Treibstoffverbrauches bei Mahdreschern unterschiedlicher Konstruktion in der Weizenernte. Tagungsband VDI - MEG Kolloquium Landtechnik, Mahdrescher, H. 38:117-24.

Korn C. 2020. Application of coupled CFD-DEM simulation to separation process in combine harvester cleaning devices. Springer, Berlin, Germany.

Korn C., Herlitzius T. 2017. Coupled CFD-DEM simulation of separation process in combine harvester cleaning devices. Landtechnik. 72:247-61.
Kotov A.V., Chaus V.P. 2010. Improvement of the cleaning system of the combine harvester when harvesting grain on the slopes. Bulletin of the Gomel State Technical University named after I.I. BY. Sukhoi. 2:3-10.

Kutzbach H.D. 2001. Combine harvester cleaning systems. Landtechnik. 56:392-3.

Kutzbach H.D., Quick G.R. 1999. Harvesters and threshers. Grain. In: B.A. Stout, B. Cheze (Eds.), CIGR Handbook of Agricultural Engineering, Volume III - Plant Production Engineering. ASAE, St. Joseph, MI, USA, pp 311-47.

Mirenko V.V., Khizhenok V.F., Rodzevich P.E. 2011. Analysis of the fan operation of the cleaning system of a combine harvester. Mech. Eng. Eng. Sci. 1:3-10.

Mirzazadeh A., Abdollahpor S, Vahed M.M. 2015. Incorporating Skewness and Kurtosis in improvement of combine harvester cleaning system performance. Int. J. Agric. Innov. Res. 3:1412-6.

Miu P.I., Kutzbach H.D. 2008. Modeling and simulation of grain threshing and separation in threshing units - Part I. Comput. Electron. Agric. 60:96-104.

Mudarisov S.G., Badretdinov I.D. 2013. Numerical implementation of a mathematical model of the technological process of a diametrical fan in a rotating coordinate system. News Intern. Acad. Agrar. Educ. 17:79-83.

Ospanov A., Muslimov N., Timurbekova A., Jumabekova G., Almaganbetova A., Zhalelov D., Nurdan D. 2019. The study of indicators of the quality test of poly-cereal whole meal flour for making pasta. J. Hyg. Eng. Des. 27:32-8.

Ostrikov A.N., Ospanov A.A., Shevtsov A.A., Muslimov N.Z., Timurbekova A.K., Jumabekova G.B. 2020. Mathematical model of high-temperature tube-shaped pasta drying in a conveyer belt drier. Int. J. Food Eng. 1 [Epub ahead-of-print].

Ostrikov A.N., Shakhov S.V., Ospanov A.A., Muslimov N.Z., Timurbekova A.K., Jumabekova G.B., Matevey Y.Z. 2018. Mathematical modeling of product melt flow in the molding channel of an extruding machine with meat filling feeding. J. Food Process Eng. 41:e12874.

Rademacher T. 2003. Mahdrescher. Die Qual der richtigen Wahl. Getreide Magazin. 3:186-91.

Sorochenko S.F.. 2017. Mathematical model of grain separation in the cleaning system of a slope grain harvester. Bull. Altai GAU. 12:134-40.

Špokas L., Adamčuk V., Bulgakov V., Nozdrovický L. 2016. The experimental research of combine harvesters. Res. Agric. Eng. 62:106-12.

Steponavičius D., Špokas L., Petkevičius S. 2008. The influence of position of the first straw walkers section on grain separation. Agron. Res. 6:377-85.

Vasilevskij M.V., Romandin V.I., Zykov E.G. 2013. Transportation and sedimentation of particles in the processing technologies of dispersed materials: monograph. Tomskij politehnicheskij universitet, Publishing House of Tomsk Polytechnic University, Tomsk, Russia.

Voicu G., Casandroiu T., Tarcolea C. 2008. Testing stochastic models for simulating the seeds separation process on the sieves of a cleaning system, and a comparison with experimental data. Agric. Conspec. Sci. 73:95-101.

Wang L., Zhang X., Leng J., Zhao G., Jiao Z., Qin Y. 2018. Fatigue life analysis of grain combine harvester cleaning device. Trans. Chinese Soc. Agricult. Machin. 49:282-7. 